\title{
Europe as a narrative laboratory. Klaus Eder on European identity, populist stories, and the acid bath of irony
}

\author{
Klaus Eder (keder@rz.hu-berlin.de) \\ Humboldt-Universität zu Berlin, Germany \\ Sören Carlson (soeren.carlson@uni-flensburg.de) \\ Europa-Universität Flensburg, Germany
}

\begin{abstract}
After an introduction by Sören Carlson that summarizes key aspects of Klaus Eder's theorizing regarding the role of narratives for the symbolic construction of "Europe" and European identity, the ensuing conversation between the two addresses some of the subsequent issues arising from this work. It thus deals, inter alia, with the concept of narrative resonance, the relation between narrative and network structures, and the (neglected) role of narratives in social-scientific thinking. It also discusses the potential of irony vis-àvis other narrative genres - such as tragedy, romance or the comic plot often used by populists - within a process of collective identity formation in Europe.
\end{abstract}

"Europe turns out to be a narrative laboratory in which narrative plots are struggling with each other. These narrative struggles offer elements for the reconstitution of a European 'we' beyond the model of a national 'we' [...]." (K. Eder, in this interview)

\section{Introduction}

The following interview with Klaus Eder, retired Professor of Comparative Sociology at Humboldt-Universität zu Berlin, Germany, and a prominent sociological voice amid the various disciplinary contributions to the narrative study of Europe, addresses his theoretical work on the role of narratives in the construction of "Europe". Eder has used the notion of narrative in theorizing about Europe's borders (Eder, 2006), the making of a European society (Eder, 2014) and the nature of the social bond (Eder, 2009a), but most notably in his work on European identity (Eder, 2009b, 2011; Forchtner \& Eder, 2017). For those less familiar with Eder's work, a short summary of his main theoretical ideas on the role of narratives in relation to Europe and Europeanization processes follows, based on his publications on this subject. Obviously, such an approach risks creating the impression of a theoretical undertaking that is more or less finalized while, in fact, it has evolved over some time, and is still ongoing. Nevertheless, in order to provide some background to the ensuing colloquy - which results from an email exchange between July and November 2019 -, it seems justified to highlight a couple of points.

Similar to other researchers interested in the link between narrative and identity (e.g. Somers, 1994), Eder's starting point is the assumption that narratives provide a form of symbolic construction that ties people together by equipping an entity (e.g. "the nation" or, 
possibly, "Europe") with meaning; this allows people to recognize each other as being part of one group, thereby creating a shared sense of togetherness and reciprocity, a form of collective "we" (Eder, 2009b, 2011; Forchtner \& Eder, 2017). In contrast to socio-psychological and normative conceptions of identity, Eder (2009b, 2011) thus argues strongly in favor of a sociological approach that conceives of identity as a form of collective identity. Furthermore, rather than perceiving identities as given and "fixed", Eder assumes that processes of identity construction and reconstruction need to be seen as an ongoing evolutionary process, fueled by narratives contradicting each other; only in specific instances as has happened historically with the idea of the nation -, is this process blocked, so that distinct collective identities can emerge (Eder, 2009b). Building on this, we can distinguish four central theoretical propositions:

First, contrary to the (postmodern) idea that narratives exist somehow on their own, more or less detached from any "social base", Eder insists that narratives and the social relations or networks, which people pertain to, are linked to each other. Thus, in order to provide the ground for a collective identity, narratives need to be embedded into social networks, so that these stories can circulate through these networks and be shared and retold among people (Eder, 2011). Applying this idea to the case of Europe, this means that emerging (transnational) networks of social relations among people in Europe serve as a base which allows the dissemination and telling of different stories, creating in effect a "narrative network" upon which the process of European identity construction rests (Eder, 2009b). Insisting on the link between narratives and social networks as a precondition for European identity formation also helps to explain why certain ideas that are often treated as a possible foundation for a European identity (such as the human rights discourse or the idea of a "social Europe") actually do not seem to work very well: such narratives are more part of intellectual, elite-based circles and, thus, rather disembedded from wider social networks (Eder, 2011, 50).

However, there is yet another side to the proposed link between narratives and social networks which goes beyond the former idea of embeddedness. Social relations also need to be seen as mediated by symbolic forms (in this case, narratives) as Eder (2009a, 77) argues, referring to Durkheim, Mauss and Lévi-Strauss. Thus, social relations are produced through the process of communicating narratives (Eder, 2007a, 189; cf. also Eder, 2009a, 74, 76). The link between narratives (as ways of bringing forth identities) and people's social relations therefore has to be perceived as two-sided: "[...] the network structure linking a people shapes the construction of the identity of that network which then is used to reproduce this network structure. Thus, collective identity constructions are a central building block of social relations" (Eder, 2009b, 430).

The second proposition is that for narratives to have an effect - that is, for identities to emerge -, such stories do not only need to be shared and retold among people, but they also have to make sense to them. This is what Eder calls (with varying terminology) "narrative plausibility", "narrative resonance" or "narrative fidelity" (Eder, 2006, 257). Such "resonance" or "fidelity" can be said to exist if the elements of a narrative are organized in a meaningful sequence, so that the claims made by this narrative (e.g. in terms of identity) appear as more or less self-evident to people. One of the factors Eder $(2006,258)$ mentions that enable such "understanding" is a shared language, but possibly one may also think here, for example, about socialization, or shared memories, as further ways of providing a common ground among people.

Third, Eder assumes that narrative forms differ with regard to their degree of connectivity with each other: narratives following a tragic or ironic plot structure tend to allow more easily a retelling and connecting of different stories about "us" and "them", thereby keeping the formation of collective identities ongoing. Comedic and especially romantic narratives, on the other hand, are prone to be less compatible with other narratives, due to 
their inbuilt tendency towards resolving antagonisms, unambiguousness and toward a happy ending. By blocking the retelling of different stories, identities can be fixed, thus contributing to the constitution of self-contained and more or less exclusive social groups (Forchtner \& Eder, 2017, 81).

This can be clearly seen in the case of national identities where "[t]he idea of the nation has succeeded in blocking the future of collective identity construction, for some time at least" (Eder, 2011, 48). This persistent salience of national identities is linked to the fact that they are usually based on narratives with either romantic or comedic structural plots. Since such plots are difficult to connect with others, identity formation beyond the national is hampered (Forchtner \& Eder, 2017, 95-97). At the same time, it seems that there are a lot of stories circulating through Europe - e.g. the story of the common market, of a unique European culture, of European integration as a way to preserve peace among formerly hostile nations, etc. However, "[a] robust narrative of the citizens in Europe connecting the stories of different individuals, groups, nations or cultures into a good new story with a good end, a story that can block the future, does not exist as yet" (Eder, 2011, 49). Nevertheless, by highlighting the role of the structural properties of narratives and their ensuing (non-)compatibility, Eder provides an (empirically measurable) way to identify those elements that might contribute at some point to the formation of such a "robust" European identity that blocks further story-telling (Eder, 2011, 49). Yet stories do not stop at some point, they encounter other stories, thus fueling the process that underlies identity construction.

Based on these previous propositions, Eder finally makes the theoretical suggestion that specific narrative structures might correspond to, and unfold in, specific network structures, thus constituting a form of "isomorphism" or "Wahlverwandtschaft" (Forchtner \& Eder, 2017, 81, 92; cf. also Eder, 2009b, 438-440). Drawing on one of the examples that Forchtner and Eder $(2017,92)$ provide for this, one may think here of the "Eurostars" (Favell, 2008), i.e. European professionals who create through their commuting activities transnational social networks in Europe, while also still being embedded into "traditional" national networks (e.g. when they return home for the weekend). According to Forchtner and Eder $(2017,92)$, such clique-like networks lend themselves as sites for the circulation of romantic stories, that is of stories about national particularities which can give rise both to the idea of (renewed) friendship between nations as well as to a rekindling of (past) hostilities. Both authors mention, however, that this suggestion of isomorphism needs to be seen, as of yet, as more of a theoretically open question (Forchtner \& Eder, 2017, 92). Based on these theoretical propositions, Eder concludes that, given the aforementioned variety of stories currently circulating in Europe, two conditions seem to be especially important for whether these different narratives might come together at some point, thus allowing for the symbolic construction of "Europe" as a meaningful entity: the further evolution of social relations across Europe and the structural properties of these narratives since these affect their narrative connectivity (Eder, 2009b, 437).

\section{Interview}

Sören Carlson: Looking at your work, one can see a long-standing interest in the sociological analysis of Europe and European integration, as is apparent in your earlier research on European citizenship (Eder \& Giesen, 2001) and a European public sphere (Eder, 2000; Eder \& Kantner, 2000), for example. However, how did you become interested in the notion of narrative and its application to "Europe"? 
Klaus Eder: The issue of identity arose quite early in my research career at a time when few scholars (including my own colleagues and teachers at the Max-Planck-Institute I worked at at the time) took it as an important theoretical issue. This interest was raised when doing research in the 1970s on national identities in France and Germany and the implications for French-German relations after the war. This was the time, when the story of a new friendship was told while carrying in the background the ambivalences of the past. The German-French "folie à deux" told two stories: one of understanding and one of disciplining emotions and mistrust. The lesson I drew in the course of time has been that no rational debate can decouple itself from the identities that are the product of the past. Identities always interfere with rational communication, and the conceptual apparatus of theories of rational communication, dominant in different versions at the time, was systematically distorted by these theories' inability to take into account the narrative basis of rational communication. This idea evolved further and ended in the assumption that any form of rational argumentation is embedded in narratives that provide the basis for seeing our ways of engaging in rational communication as natural. Thus, without looking into these unspoken naturalistic assumptions, we cannot understand why rational communication succeeds or fails. It succeeds best when those communicating with each other share a narrative that is fixed (by blocking the narrative course of events), i.e., by constructing a collective identity. It fails when such an identity is not given. These extreme cases point to the role of narrative underpinnings: since narratives evolve, identities dissolve and are remade, and the conditions for success or failure of communication change.

The application of this theoretical perspective to Europe is obvious: Europe is based on competing narratives, many of them blocked and fixed as national stories of being a "we", and there are attempts to impose another narrative hoping to fix it as a European identity. Yet these attempts did not succeed so far in superimposing themselves upon the existing narratives circulating in Europe. On the contrary, if you take the citizenship narrative as an example (i.e. the idea of creating a shared sense of togetherness via the institutionalization of European citizenship), it opened the door to competing stories of who is a citizen and who is not, who is a good citizen and who is not, thus opening Pandora's box of multiplying narratives of being a citizen (Eder, 2017). The effect of this pervades the Europe of today, undermining the world of rational politics of the EU and rational debate about it.

Sören Carlson: To me, the specifically sociological angle in your theorizing on narratives is, as described above, your insistence on the relationship between social networks and narratives, that is between the structural and the symbolic dimensions of social life (which reminds me to some extent of Bourdieu's efforts to overcome the division between "objectivism" and "subjectivism"). While it seems obvious to me that a) the diffusion and retelling of narratives depends on social networks (or a shared communicative space, cf. Eder, 2007b, 2011, 44) and b) social relations are shaped by symbolic processes, maybe you could still elaborate a bit on how exactly you perceive this relationship?

Klaus Eder: The difference between stories and networks is an analytical one. People enter social relations not by their mere physical presence, but by sense-making activities (communicating that you are a friend, that you are coming from somewhere, etc.). Sensemaking requires words that circulate. These words can be organized as arguments (but you normally do not enter social relations by forcing the other to take a stance on an argument) or as stories (that give sense to the words exchanged with others). Then stories (or, in some cases, arguments) can widen the circle, diffuse to other members of a network (people tell other people of the story that the newcomer has told, etc.). In some situations, these words are organized as political stories (or, in some cases, arguments) that establish or destroy social relations. What is important is that these stories or arguments are not 
invented ad hoc, but that they follow in form specific rules and in substance definitions of what is right or wrong or true or false in the social world people live in (such as a village, a nation, or a culture). The important point in my writings for two decades has been that storytelling is underrated theoretically in terms of making sense of social reality and that it might be constitutive for being able to argue with each other. In the theory of communicative action, this idea is taken for granted or, more exactly, it is argued that such narrative bonding is dissolving increasingly in the course of the rationalization of life worlds. Yet, it is not dissolving. On the contrary, it continues to shape human social relations as ever. Thus, in short, one may say: there are no social networks that can decouple themselves from narrative presuppositions. On the contrary, networks are the medium for the permanent processing of its narrative foundations.

Sören Carlson: Your idea that narratives must have some kind of "narrative resonance" with people in order to have an effect intuitively makes sense, and it also provides a good antidote to the idea that just any narrative can be "sold" to the people. However, this still raises a number of questions: how can such "narrative plausibility" actually be determined? How can we understand its origins and "production" - without generically referring to "culture"? And, finally, how might such "narrative resonance" change?

Klaus Eder: The concept of narrative resonance risks fostering a simplification that threatens to undermine the theoretical intention of taking seriously the narrative dimension in social life. It insinuates that there is a storyteller who provides stories that people like. But narrative resonance means that those talking to each other "resonate" to the story (not to the storyteller!) that is circulating (see Schudson in a famous article of 1989, media resonance studies in general, and social movement studies focusing on the aspect of framing). If there was no narrative resonance, no social relation could be established or upheld. Then it makes sense to argue that participants in narratively grounded social relations start to make instrumental use of such stories trying to mobilize followers (the social media are based exactly on this mechanism). Whether they do it because they want power, or because they want to proselytize the other, is secondary here. Narratives can always be used for strategies to bind people into narrative echo chambers. Resonance is an indicator for the degree to which people follow particular stories, be they populist, religious, conservative, racist, and so on. When a specific story starts to attract more people, then public opinion shifts, producing ruptures in the way social relations are reproduced. The narrative model simply claims that the type of narrative genre that gains in importance determines the pathway for the further evolution of social relations.

Sören Carlson: This clarifies the idea of "narrative resonance" to a certain extent, but I am not fully satisfied yet. To me, there still seems to be something missing that could account for how and why the resonance of some stories changes over time. After all, throughout history rather different stories about, for example, who is part of society, and what its legitimate order is, have circulated and differentially resonated with people. Your previous answer implies that this change should not be simply ascribed to the (rational) exchange of arguments, but how can we then explain shifts in narrative resonance or why some stories assert themselves over others? What about societal relations of inequality or power in this context?

Klaus Eder: This is the most difficult question, since it asks for the role of narrative structures in processes of social change. We do not have to explain social change, since it happens permanently. Events such as wars, economic exploitation and symbolic violence (racism) provide particular moments of disorder that provoke repair. Repairing social 
relations is thus the process to be explained. A strong theoretical argument (which I would like to defend) is that narrative structures shape the paths of social repair. The problem is not that narratives change. Rather, the problem is which narrative wins over others, thus changing the conditions for further social repairs. A narrative explanation starts with the assumption of a limited number of genres that shape the way social relations are ordered and reordered. And it claims that narratives provide a way to look into the mechanism producing the outcome of social repairs.

In this version, the theory is still naked ("merely" structural). But narratives do more than just provide a form for telling stories. Narrative genres are like grammars that organize the way people tell each other about the world. Genres organize stories on what moves social actors, i.e. on ideas and emotions; they are about actors helping and fighting others, doing good or bad things, being betrayed or betraying others, being altruistic or egoistic. Narratives tell about the way how these ideas and emotions are processed over time and tell about the outcome of conflicting ideas and emotions. Thus, tragic stories relate how actors are confronted with tragic choices, keeping open the outcome of social repair. Romantic narratives generate stories which tell how actors will finally overcome disorder, reaching collective salvation from disorder by fighting the devil in their ranks. Comic narratives bring forth stories that tell how people succeed to live together in peace after turmoil; they differ in defining the hero leading the people to such an outcome, be it good kings, democratic assemblies or solidary communities, yet the plot remains the same. Finally, ironic narratives tell stories that undermine established stories, thus opening the social world to thinking of better worlds.

Linking narrative theory to collective learning (in the Habermasian tradition) offers an important addition to enhance the explanatory power of the mechanism of social repair (beyond the program of advancing a theory of collective learning). Learning and non-learning are cognitive processes that happen when social actors engage in storytelling. Learning, the theory holds, happens when rational debate and reciprocal recognition guide the resolution of conflicting ideas and emotions. Non-learning occurs once emotions such as hate or ideas such as racist superiority enter a narrative. Both, learning and non-learning, are part of the mechanism of social repair. The social world consists of both, rational debate and symbolic violence, reciprocal recognition and racist superiority claims. Even the story of the Enlightenment does not escape this double nature of human sociality, as Horkheimer and Adorno (1947) have pointed out by highlighting the dialectic nature of cognitive processes occurring in this context. Obviously, such ideas have an equal force in social life. Yet, narrative genres are differentially conducive to learning or non-learning: the basic theoretical hunch here is that romantic narratives are the most immune to learning, while ironic narratives are the most open. Learning happens when heroes are not sure about what to do best, and when the outcome is disconcerting. However, if the hero is "pure" and the outcome is beyond doubt, non-learning is the more likely outcome.

Thus, the theory that narratives are a mechanism of social repair (or social change in an old-fashioned language) simply states that, in times of social disorder, repair follows a path that is determined by two factors: cognitive input (good and bad) and its genre-specific narrative organization. And then we can make conjectures about the type of repairs that will be enacted. For example, democracies enact repairs by mobilizing the will of the people as the legitimating ground for political action. This collective will can foster either learning or non-learning, depending on the way this collective will is "narrated". This means that the popular sovereign (as the legitimating ground of democratic politics) does not escape this ambivalence which points to the basic vulnerability of democratic forms of social repair. It depends, I would argue, on the narrative organization of the conflict between good and bad, whether learning will be fostered or blocked - and not on the built-in goodness of the good (the crux of normative theories of social life). 
One might detect here a "normative rest" in narrative explanation, which is to say that learning is better than non-learning. But there is a self-defeating mechanism at work here: learning might end in tragic choices, and we do not know in advance how to proceed. Any cognitive reassurance or even claim of superiority, based on "having learned" something (be it lessons of the past or lessons of the present), is basically undermined by the ironic genre (an excellent discussion of such self-defeating learning is found in Forchtner, 2016).

Sören Carlson: Looking at the four theoretical propositions mentioned in the introduction, the last one, i.e. the assumption of a form of isomorphism between specific narrative and network structures, seems theoretically the most far-reaching, but also the most tentative one. Therefore, let me ask you more principally: why assume such an isomorphism at all, why is it theoretically deemed as necessary? And how would such an isomorphism relate to the aforementioned issue of narrative change?

Klaus Eder: It is theoretically clear how the proposed isomorphism works. It is a simple feedback effect: ideas shape social relations, and social relations shape ideas. The interesting theoretical issue is how this feedback unfolds in time and the cumulative effects over time. The theory is that social relations are constituted through storytelling and therefore the form of the story (the narrative structure) is expected to be "reflected" in some way in the form of social relations. In a recent paper (Forchtner, Engelken-Jorge \& Eder, 2020), we argued that we can distinguish four forms that structure stories. These forms are shaped by two parameters, the purity/impurity of the hero and the reassuring/irritating course of the story line. Combining these dimensions, we arrive at four types of narrative structures, i.e. "genres". These genre-specific stories provide models of social relations: they define boundaries of the group sharing such stories and they define hierarchies within that group. In these social relations, stories continue to be told and retold, adding new events/actors to the stories, and at times even redefining the boundaries of a group (be it more inclusive or more exclusive boundaries) and/or its internal hierarchies (be they flatter or steeper). There is a reciprocal link between narrative forms and social forms.

This reciprocal link is not fixed in time, however. The narrative reproduction of given social relations can succeed or fail (as it happens with mutations and selections in biological reproduction processes). Stories are retold, while social relations (such as a stable postwar middle-class culture) in which these stories circulated (such as postwar individualism) actually break apart. The reproduction of an isomorphism can thus be confronted with either a narrative shift which social relations no longer accommodate or with a change of social relations that unmakes the resonance to the old stories into which people were socialized. It is to be expected that such ruptures are less common than re-adaptations. We will always find examples of both order (stable isomorphism) and crisis (unstable isomorphism), if we expand the time frame and the spatial range of analysis.

Based on this, two implications for explaining the dynamics of present-day societies can be identified. The first is that the narrative foundation of modern societies varies - as it did in premodern societies. On the one hand, it can be based on stories that link the figure of the "pure" hero and reassuring outcomes with highly (hierarchically) ordered social relations that do not allow for deviance. On the other, modern societies may rest on stories that combine "impure" heroes and irritating outcomes with social relations in which people live in more egalitarian and open forms with each other, allowing larger fringes of selfdetermination and subjectivity. The second implication concerns the question of explaining the consequences of narrative shifts that point either toward the pure or impure end of the realm of possible narratives. The hypothesis deriving from this and to be tested empirically is as said above: narrative orders are reconfigured given social disorders and it 
depends on the type of narrative shift what kind of social world emerges. Taking seriously the idea of isomorphism, we can thus conjecture that a return to romantic genres in modern societies will lead to social relations characterized by rigid hierarchies and strong divisions between the "pure" and the "impure" people. Intuitively, we know that. But to explain why this is so, the narrative approach might give an answer.

Sören Carlson: Within your work, you have argued for a structural approach to the analysis of narratives, thus for a focus on structural characteristics (e.g. reconstructing plot structures or genre types such as romance, tragedy, comedy, or irony), rather than on content or the discursive strategies used in order to achieve a compelling representation (Eder, 2011, 53; Forchtner \& Eder, 2017, 80, 98). Why do you give preference to such a structural approach or, rather, where do you see its specific advantage(s) vis-à-vis a more contentoriented analysis?

Klaus Eder: When we look only at content, then the complexity of the world is hard to disentangle. People tell so many different stories varying in situations, scale, etc. that research will end up in theory-free compilations of stories varying in time and space. Since I assume that the production of stories is not an anarchic creation of words and word combinations, but that it rather follows specific rules (not only of grammar, where this is obvious), we have the possibility to avoid getting lost in the err-garden of mere words. The theoretical hunch is that narratives not only correspond to a specific type of social relation linking individuals and separating them from other networks of individuals (this refers to the dimension of being inclusive or exclusive), but also to a specific type of the evolution of social relations (open versus closed futures, progressive versus conservative ways of imagining the future). That content matters, I would never contest. On the contrary: structural analysis without concrete content remains a glass bead game. Already the "Mythologiques" by Claude Lévi-Strauss (1964-1971), one of the finest examples of structural analysis, lives of its contents, i.e. the stories of the Indians. The ideal form of analysis is to show the variety of contents within structural narrative patterns, thus providing information on which story content is possible, given a finite set of narrative structures.

Sören Carlson: In one of your more recent publications on narratives and European identity (Forchtner \& Eder, 2017), it seems that you favor to some extent the narrative genres of tragedy and irony, since these could provide a way out of the current impasse in Europe created by traditional "national" stories that follow a romantic or comedic plot and thereby tend to reproduce national perspectives and exclusion of "the other" (cf. also Eder, 2009b). Tragic and ironic plots, in contrast, open up possibilities for self-reflection and collective learning, thus allowing the connection of different narratives, and can help to overcome (national) self-righteousness - so goes your argument. At the same time, you assume, however, that tragic and ironic stories are not very good at blocking ongoing processes of identity formation. If one also looks at current social and political developments in Europe - whether Euroscepticism, populism, right-wing extremism or corresponding countermovements -, it seems that there is not much space left for irony. Thus, how do you think the further narrative construction of European identity might unfold?

Klaus Eder: National stories follow the comic plot, in some cases the romantic plot. Romantic plots give to comic plots a wider time dimension, claiming to tell how the past will move toward an unavoidable future. Romantic plots are particularly prone to what we could call reactionary or racist stories. They define clear boundaries within which people as the story says - "live forever in peace". The historical experience has not been sufficient to undermine the belief in such romantic stories - they regularly return when a horrible 
past tends to be forgotten. European identity constructed along the national model will certainly not be different: it promises to provide peace and happiness forever for the people living in this space. As a story promising a closed space over time, it must collide, however, with other non-European identities, be they American, Chinese, etc. or from migrant people who are forced to move. Therefore, the search for a European identity continuing along the lines defined by the nation-building process is a highly ambivalent project.

This raises the question of whether there are alternatives to comic stories turned into romantic stories. I have ventilated the idea of the citizenship story as an open story that could be the basis for a European identity based on fluid boundaries and fostering the permanent unblocking of the future, allowing to engage in the permanent reconstruction of a collective identity (Eder, 2017). But this is theoretically not very satisfying, since this story does not prevent European identity formation from ending up as a supra-national story, as a national story on a higher scale.

Given the fact that people do not necessarily have to live in the national container (they can live in enlarged families, in diasporas, in migrant communities), theory needs to provide a framework to think of alternatives to the national experience of constructing a "we". Narrative theory offers two alternative genres for this: the tragic and the ironic genre. The tragic genre produces stories in which morally appropriate deeds turn into morally disastrous deeds (the classic case is Oedipus). After the tragic event, the participants (to the extent that they survive) might learn from the tragic event. Thus, tragic narratives contain equally the option of failure and the slim option of a new beginning, thereby adding a reflexive dimension, namely of redoing things differently. An example in today's Europe would be the story of Brexit, that could be seen (beyond the dominant "comic", at times "romantic" story of liberation from the claws of Europe) as a tragic story of colliding ways of doing the good. "Tragic" does not mean that the hero of a story is a morally bad actor. What counts is the morally disastrous outcome of good-willing actors. Tragic means that what we want clashes with the will of what others want, and both wills are legitimate. Tragic is (quoting Amos $\mathrm{Oz}$ ) the clash between right and right. It forces us to see that, for example, wanting to be good Britons, good Europeans, or both, entangles actors in a situation that nobody wants. Such experiences enhance the chance for reflexivity and learning, but they cannot guarantee such outcomes; instead, people might return to the comic story. Such narrative moves, dissolving the tragic moment into a comic one, in fact fuel public debates, not only in the British case, but even more so on the European level. Europe emerges as a space for a cacophony of comic (and romantic) narratives. The comic genre is the generative logic of the stories told by Emmanuel Macron or Angela Merkel (to use names as proxies for stories), while the romantic genre organizes stories with heroes such as Marine Le Pen, Viktor Orbán or Matteo Salvini. At times, Europe also invents new tragic stories, e.g., in the stories told by people identifying as European Jews or European Muslims. This is still a rare case of retelling the tragic elements in European history, reopening the issue of how "we" want to live with the "others" for the time to come. "Never again" means learning from past events and creating a new bond among the people constituting a "we".

Europe turns out to be a narrative laboratory in which narrative plots are struggling with each other. These narrative struggles offer elements for the reconstitution of a European "we" beyond the model of a national "we" as told in comic or romantic stories. Tragic stories add something new to the making of a European identity: to see Europe as the outcome of a tragic story being involved in a kind of Odyssey.

However, there is still another way of telling events that goes beyond the limits of the romantic, comic and tragic genres which is - linking back to your question - irony. Irony provides not only a way of undermining the strong belief in the final salvation of the people (which is the message of stories based on the romantic genre). It also provides elements 
for learning from the failures that are built into the stories emerging from the comic genre, thus guaranteeing a permanent retelling of the story as a "comic story". Irony helps to continue living together after the tragedy, since it can create imaginaries for new bridges between the past and the future. Irony thus helps to bear the tragic past and to open up new modes of experimenting with living together.

Finally, irony also allows us to look at storytelling as a not so serious thing. The ironic point of view makes existing stories easier to acknowledge, tolerate, and criticize. In this sense, Brexit - turning from a potentially tragic story back into a comic one (or even into a romantic story as some public utterances by Boris Johnson in 2019 indicated) - can be looked at with an ironic eye: from playing ironically with the tragic images such as the Brits sacrificing themselves for the good in the world to the bright future that is promised to continue a wonderful past. Stories using ironic plots, including jokes, tell events in such a way that people laugh and look at each other less seriously. Irony also fosters the reciprocal acknowledgment of differences (see as a provocative narrative analysis pointing into this direction Nicolaïdis, 2019).

Overall, we can thus observe that the making of a European identity today takes place in a narrative space, where comic and romantic stories (mainly as nationalist stories) grow, and where tragic stories carrying the burden of the past retreat. Circulating ironic interpretations of comic, romantic and eventually tragic stories could create a space of communication, however, where irony enables us to play with stories. This undermines stories that assume a clear boundary of the people in Europe and a final future of this people. Playing with stories also allows us to continue to live after the tragic events. Constructing a European identity in such a narrative space opens a chance to unblock the future of the people living in this space. European identity in this sense would then be constituted by a reciprocal mirroring of stories, exposing the tragic self-interpretation of comic and romantic stories to the ironic eye, and thus opening the comic stories toward shifting boundaries and futures. In one word: European identity is based on a "we" which acknowledges the competing stories circulating within this "we", by introducing the ironic eye. The outcome would be a learning process transcending the false promises of romantic stories, the banality of comic stories, and the limits of tragic stories. The outcome would be a people capable of living with shifting boundaries and open futures, constructing its collective identity as a never finishing process.

Sören Carlson: Independently of the question of narrative forms, it is often argued nowadays that Europe needs a "new narrative" in order to provide social cohesion among EU citizens, as the "old" stories of peace and prosperity for all, resulting from European integration, are seen as insufficient or having lost credibility (cf. Bouza García, 2017). Despite your critical attitude towards the idea that narratives can simply be implemented in a topdown fashion, the idea of a missing narrative that could bind people together is mirrored to some extent in your article on the societal effects of the different crises in Europe (starting around 2008 with the so-called economic and financial crisis): here you state that we can indeed observe an increasing interconnectedness among the European people (thus satisfying the precondition of existing social networks through which narratives can circulate), but that "there are no ideas that flow through these emerging social relations that could provide the sense of togetherness of a highly diverse people" (Eder, 2014, 228). In contrast to that, Bouza García $(2017,346)$ argues that there is not really a shortage of narratives, but rather that the very structure of segmented European public spheres limits the circulation and generalization of these stories. These are rather contrary conclusions. Thus, what do you think: do we still lack a (convincing) European narrative, or is it something else entirely? 
Klaus Eder: The issue here is what we understand as "ideas". Narratives of peace and prosperity as well as narratives of order permeate Europe today, and they articulate needs and hopes that probably are universal. National narratives promise this, religious narratives have always done so and continue to do so, and "European" narratives certainly will do so, too. There is nothing in these "new" narratives, however, that could provide a sense of togetherness beyond the old promises offered by nations or religions. I was talking in the quote above about an idea that could provide a sense of togetherness among the diverse people in Europe. This idea must be more than a repetition of what religious or national narratives have told us. We can search for such an "idea" in terms of different contents, something going beyond order, welfare, or peace. This search has nourished narratives telling us about the values that Europeans share and that others do not share (at least not to the extent that Europeans do). Such ideas are either very general such as "freedom", "human dignity", and the "recognition of the individual" or more concrete, e.g., about the way in which the family and relations among the sexes should be organized. Furthermore, the idea of a "social Europe", an "ecological Europe", or of Europe as a "normative power" have turned up, "ideas" that circulate through the media in the midst of a cacophony of voices throughout Europe. However, the search for a European identity based on such "ideas" is a dead road. You can share or contest ideas. Yet, constructing a "we" requires more than shared ideas.

Following the theoretical lead proposed above, it is not ideas as such, but narratives that contextualize ideas. The narrative plot that dominates, at least in Western societies, is the comic plot. Comic stories tell that "we will make it" if we are good to each other. This is the plot of standard EU-Europe. Romantic plots narrating an unavoidable future in which the people become one people across generations exist, such as the story of a Europe without war or a Europe without injustice (and today a Europe producing a sustainable world). Tragic plots mark a point in the past which needs to be "overcome", thus constructing a tragic Europe, capable of reflecting upon and rectifying its past. These options for a European identity differ from religious or national identities by identifying a different "we", yet they do not escape the logic of the plot that underlies these constructions. Then there remains the theoretical idea of irony as a plot for constructing a "we" that goes beyond the "serious" narratives of who we are in Europe.

My statement that you cite - that there are no ideas that could circulate - therefore needs theoretical specification (it is too simple when formulated in this way). I would argue that there are a lot of ideas around and that there is even a space in Europe where ideas can circulate. There is a clear node in the network of social relations in Europe that links ideas such as peace, order, or welfare to social relations that exist beyond the local or national container. This node is the political system (the "state"), the EU legal and administrative machinery. Beyond this obvious node that affects (positively and negatively) most Europeans, there is a public space (including its digital extensions) emerging in Europe in which a lot of voices refer to Europe. But there are few narratives that focus on Europe as such. One of these is the narrative of the "Islamization of Europe", another is the Europe of the Enlightenment, still another a Europe suffering and overcoming its horrible past. Thus, there are narratives that circulate in Europe, and the problem is not one of segmented public spheres that do not communicate. In fact, the opposite is emerging if we look at the intensity with which the European neighbors (i.e. nation state publics) observe each other. Most people in Europe can associate a specific story with names like Viktor Orbán. Then the issue is not the lack of ideas, the lack of narratives, nor the lack of social relations transcending the national container. The issue is which narrative will win over others. The options and their respective costs are clear. The process of further Europeanization will be shaped by which of the many "ideas" circulating in European society are organized into a narrative, defining the boundaries and futures of the people in Europe. The right-wing 
parties in Europe try these days to create a European narrative based mainly on the idea of order, whereas the left-wing parties in Europe fail in making prosperity the core of a transnational story; the left seems to be fixed to the national level and its comic or romantic stories. Counter-stories against the right-wing narratives emerge too, mainly in the context of the ecological issue, and their narrative success and potential hegemony must be seen.

In any case, the confrontation of many stories circulating in Europe offers the possibility to invent narratives of reciprocal acknowledgement and recognition. This language is certainly not found in the new romantic plot that has made Europe the (normative) telos of the world. It is not a comic plot that makes Europe the best place to live in the world. Neither is it a tragic plot since tragedies do not tell what to do afterwards. What remains? The ironic plot? Theoretically a possibility to test, yet from a normative point of view a provocation.

Nevertheless, the idea of an ironic plot can hook upon a series of observations of presentday digitally mediated political communication. We are normally geared to see public responses to political events as "shit-storms", reacting with moral denigration and devaluation. On the other hand, there are equally communicative counter-mobilizations that try to hold against shitstorms. They have a hard time holding the moral positions they defend. Mobilizing support for fair treatment and appropriate ways of solving conflicts do not impress the other side, which often consists of large parts of national electorates. The moral cudgel no longer works to get out of the irreconcilable positions people have run into. Telling a moral story collides with the moral story of the others.

The ironic plot offers a different way of communicating irreconcilable positions, however. We find it in the new digital counter-publics, a site that so far has remained at the margin of political discourse. Comments on what the new "stars" in political discourse - be it Donald Trump, Matteo Salvini, Boris Johnson, or any other of the new "authoritarians" (or sovereigntists) - are doing, become successful when couched in an ironic language. We know how in the past irony has been perceived as dangerous by authoritarian regimes and how harsh the attempts of suppressing irony have been. In the digital age, irony can become a force of undermining the new comic stories of the non-liberals (see Trump's twitter stories of who the heroes and who the losers are) and the romantic stories of the new nationalists (see Johnson's way of legitimating Brexit), a force much better suited to keep talking with the "enemy" than the moral cudgel that dominates the liberal critique of non-liberal political positions. Furthermore, irony is not only to be found in social media. It is also in traditional mass media where it serves the function of opening up political communication about often irreconcilable discursive positions.

For all these reasons, the ironic plot deserves closer theoretical attention when looking at Europe and at processes of constructing collective identities. It could be a way to reopen blocked constructions of collective identity and provide collective identities that are neither substantialist, nor random, nor fluid. To be both at the same time, fixed and fluid, is conditional for making and remaking collective identities, and irony provides the reflexive distance to playing with these contradictory modes of existence of collective identities. Europeans in this theoretical perspective know who they are by going through the acid bath of ironic relativization of who they are.

Sören Carlson: On the one hand, we can generally observe a revived scientific interest in narratives, as a result of the (not so recent) "narrative turn" in the humanities and social sciences (cf. Kreiswirth, 2005; Hyvärinen, 2010), and also a noticeable interdisciplinary interest in working with the notion of narrative specifically in relation to Europe. Even the EU itself has become interested in narratives as it is assumed that these might provide a way of increasing social cohesion among EU citizens (cf. Bouza García, 2017). 
On the other hand, however, it seems to me that sociology, especially the so-called sociology of Europe (or "Europasoziologie" in German), has so far shown only little interest in analyzing "Europe" from a narrative perspective - apart from your own work and that of a few others (e.g. Forchtner \& Kølvraa, 2012; Trenz, 2014, 2016). How would you account for this apparent mismatch?

Klaus Eder: The lack of concern with narratives in the context of the social sciences dealing with Europe has to do firstly with the dominance of a normative perspective. This characterizes the political science perspective as well as the sociological perspective in which narratives appear as an expression of deviance from the liberal model of talking politics. They are considered to foster irrational forms of talking about politics. The narrative appeared as the enemy of rational and/or reasonable action. It was seen just as "literature". This certainly is no longer the case (see as a provocative reinterpretation the argument for lyrical sociology by Abbott, 2007a). Yet this anti-literary (or in my parlance anti-narrative) stance has hampered the narrative turn in the social sciences. Secondly, the individualistic premises of the social sciences (well explicated and criticized by Abbott, 2007b) have not been conducive to the idea that collective identity might become more than the sum of individual preferences. Conventional analysis still looks at identity in terms of quantifiable identifications of individuals (of individual motives) and is happy with such information. To really push the narrative turn, methodological innovations are needed to make the collective character of social life visible, ranging from the structural analysis of talking to the structural analysis of social relations. So far, the methodological dominance of individualistic analyses can easily dominate the hand-made style of doing a different type of analysis, which is therefore much less legitimate than established methodological creeds. Accepting this, the costs for doing social theory are high, notwithstanding some theoretical side streams such as systems theory, a Bourdieu-style field theory, and similar closed theoretical schools. Theorizing going beyond individuals having social motives is waiting for new methodological strategies to show the collective character of "things" such as collective identity, emerging in open spaces or in echo chambers and stabilizing them in turn.

Sören Carlson: Linked to the previous question, do you think sociologists should then be (more) interested in the notion of narrative when studying "Europe"? If so, which specific advantages does a narrative approach provide to the study of "Europe" from your perspective?

Klaus Eder: If we want to understand and explain the present upsurge of ideas of the last century and before in public/political debate, and the readiness of significant parts of the population to share such ideas, we need different tools than those that are standard in sociology/political sociology/political science. A social-scientific look at Europe is more than to take the normative point of view and deplore what is happening. Looking at Europe today, we have a historical laboratory for theorizing and analyzing the discursive waves, the narrative resonances, in one word: a laboratory of how "the people", this fundamental category of the analysis of modern societies, come into being, how it divides itself and how it reproduces social relations of power and inequality. Europe would be a good opportunity for producing better theories and more appropriate methodologies.

Sören Carlson: This leads me to ask you finally which future research directions and (theoretical) issues you see in relation to the narrative study of Europe? 
Klaus Eder: Making sense of the nationalist rhetoric in a transnational situation, explaining the rise and fall of the liberal rhetoric, and providing a theory explaining the making and unmaking of the people's will.

\section{References}

Abbott, A. (2007a). Against narrative: a preface to lyrical sociology. Sociological Theory, 25(1), 67-99.

Abbott, A. (2007b). Mechanisms and relations. Sociologica (2). doi: 10.2383/24750.

Bouza García, L. (2017). The "new narrative project" and the politicisation of the EU. Journal of Contemporary European Studies, 25(3), 340-353.

Eder, K. (2000). Zur Transformation nationalstaatlicher Öffentlichkeit in Europa. Von der Sprachgemeinschaft zur issuespezifischen Kommunikationsgemeinschaft. Berliner Journal für Soziologie, 10(2), 167-284.

Eder, K. (2006). Europe's borders: the narrative construction of the boundaries of Europe. European Journal of Social Theory, 9(2), 255-271.

Eder, K. (2007a). Die Grenzen Europas. Zur narrativen Konstruktion europäischer Identität. In P. Deger \& R. Hettlage (Eds.), Der europäische Raum. Die Konstruktion europäischer Grenzen (187-208). Wiesbaden: VS Verlag für Sozialwissenschaften.

Eder, K. (2007b): Europa als besonderer Kommunikationsraum. Zur Frage der sozialen Integration einer kulturell heterogenen Gemeinschaft. Berliner Journal für Soziologie, 17(1), 33-50.

Eder, K. (2009a). Rational action, communicative action, and the narrative structure of social life. The social embeddedness of discourse and markets - a theoretical essay. In S. Ó Tuama (Ed.), Critical turns in critical theory. New directions in social and political thought (63-79). London: Tauris.

Eder, K. (2009b). A theory of collective identity: making sense of the debate on a "European identity". European Journal of Social Theory, 12(4), 427-447.

Eder, K. (2011). Europe as a narrative network: taking the social embeddedness of identity constructions seriously. In S. Lucarelli, F. Cerutti \& V.A. Schmidt (Eds.), Debating political identity and legitimacy in the European Union (38-54). Abingdon: Routledge.

Eder, K. (2014). The EU in search of its people: the birth of a society out of the crisis of Europe. European Journal of Social Theory, 17(3), 219-237. 
Eder, K. (2017). European citizenship and identity politics in Europe: is the citizenship narrative a good plot for constructing the collective identity of the people living in Europe? In J. Mackert \& B. S. Turner (Eds.), The transformation of citizenship. Vol. 2: Boundaries of inclusion and exclusion (152-168). Abingdon: Routledge.

Eder, K., \& Giesen, B. (2001). Citizenship and the making of a European society: from the political to the social integration of Europe. In K. Eder \& B. Giesen (Eds.), European citizenship. National legacies and postnational projects (245-269). Oxford: Oxford University Press.

Eder, K., \& Kantner, C. (2000). Transnationale Resonanzstrukturen in Europa. Eine Kritik der Rede vom Öffentlichkeitsdefizit in Europa. In M. Bach (Ed.), Die Europäisierung nationaler Gesellschaften. Sonderheft 40 Kölner Zeitschrift für Soziologie und Sozialpsychologie (306-331). Opladen: Westdeutscher Verlag.

Favell, A. (2008). Eurostars and Eurocities: free movement and mobility in an integrating Europe. Malden: Blackwell.

Forchtner, B. (2016). Lessons from the past? Memory, narrativity and subjectivity. London: Palgrave Macmillan.

Forchtner, B., \& Eder, K. (2017). Europa erzählen: Strukturen europäischer Identität. In G. Hentges, K. Nottbohm \& H.-W. Platzer (Eds.), Europäische Identität in der Krise? Europäische Identitätsforschung und Rechtspopulismusforschung im Dialog (79-100). Wiesbaden: Springer VS.

Forchtner, B., Engelken-Jorge, M., \& Eder, K. (2020). Towards a revised theory of collective learning processes: argumentation, narrative and the making of the social bond. European Journal of Social Theory, 23(2), 200-218.

Forchtner, B., \& Kølvraa, C. (2012). Narrating a "new Europe": from "bitter past" to selfrighteousness. Discourse \& Society, 23(4), 377-400.

Horkheimer, M., \& Adorno, T. W. (1947). Dialektik der Aufklärung: philosophische Fragmente. Amsterdam: Querido.

Hyvärinen, M. (2010). Revisiting the narrative turns. Life Writing, 7(1), 69-82.

Kreiswirth, M. (2005). Narrative turn in the humanities. In D. Herman, M. Jahn \& M.-L. Ryan (Eds.), Routledge encyclopedia of narrative theory (377-382). Abingdon: Routledge.

Lévi-Strauss, C. (1964-1971). Mythologiques. 4 Vol. Paris: Plon.

Nicolaïdis, K. (2019). Exodus, reckoning, sacrifice: three meanings of Brexit. London: Unbound.

Somers, M. (1994). The narrative constitution of identity: a relational and network approach. Theory and Society, 23(5), 605-649.

Schudson, M. (1989). How culture works: perspectives from media studies on the efficacy of symbols. Theory and Society, 18(2), 153-180. 
Trenz, H.-J. (2014). The saga of Europeanisation: on the narrative construction of a European society. In S. Börner \& M. Eigmüller (Eds.), European integration, processes of change and the national experience (207-227). Basingstoke: Palgrave Macmillan.

Trenz, H.-J. (2016). Narrating European society. Toward a sociology of European integration. Lanham: Lexington. 